\title{
On Sustainable Development of Industrial Clusters
}

\author{
Arvind $\mathrm{Kumar}^{1} \&$ Lokesh Kumar ${ }^{2}$ \\ 1, 2. Department of Mathematics, Indian Military Academy, Dehradun
}

\begin{abstract}
This paper discusses the concepts and methodology used in the system theory and operations research in respect of planning and control of the sustainable development. The sustainable development of any industrial park is not achieved merely by the introduction of foreign capital and embedding into global value chains system. Any sustainable development problem can be represented mathematically using the concepts of transition of system from the given initial state to the final state. It is established in this paper that sustainable development represents a specific control problem. The aim is to keep the system in the prescribed feasible region of the state space. Further the analysis of planning and control problems of sustainable development has also shown that methods developed in the operations research such as multicriterion optimization, dynamic processes, simulation and goal programming etc. are more than adequate.
\end{abstract}

Keywords: Sustainability, sustainable development, systems approach, multiple criteria optimization, state transition.

\section{Introduction}

"We cannot have an ecological movement designed to prevent violence against nature, unless the principle of non-violence becomes central to the ethics of human culture"

( Mahatma Gandhi)

The concept of sustainable development was first proposed in the Conference on the Human Environment in Stockholm in 1972. Later many scholars have researched the concept from perspectives of natural, social, economic, and technological attributes. In 1987 the World Commission on Environment and Development defined sustainable development as: "Meeting the needs of our generation without compromising those of future generations to develop." There are two basic concepts in this definition: First of all, human kinds, especially the poor, need development. Second, the development has to be controlled and can not endanger future generations. As per Rio declaration

"People are entitled to a healthy and productive life in harmony with nature"

It has to be compatible with social progress in order to achieve the continuous ecological, social, and economic reunification.

"You have to decide whether development means affluence or whether development means peace, prosperity and happiness". (Sunderlal Bahuguna)

The sustainable development concept should prevent the creation of social inequalities, prevent harm to the environment and permit sustaining an efficient economic basis.

Sustainable development should permit the preservation of natural capital to provide intergeneration equality. The market mechanism makes the natural capital poorer and devastates it. The sustainable development concept should specify limits to population growth and to the total demand for resources.

Sustainable development has to provide social equality in health insurance and free-of-charge education opportunities first of all. What is also crucial is attaining participative democracy in decision making.

"You must be the change you wish to see in the world"

(Mahatma Gandhi)

\section{Fundamentals Of Sustainable Development In The Context Of The System Theory And Operations Research}

State and state transition. Sustainable development can be defined as the finite-state general system, i.e. by the modified state transition function and output (read-out) function. As per Heuristic definition state is the set of data, giving complete information about the system history necessary for the determination of its behavior in the future, providing the management or control actions are known.

The state transition function is given by the expression

$\mathrm{x}_{\mathrm{k}+1}=\mathrm{f}\left(\mathrm{x}_{\mathrm{k}}+\mathrm{x}_{\mathrm{k}-1}, \mathrm{u}_{\mathrm{k}}\right)$

and system output function is

$\mathrm{y}_{\mathrm{k}+1}=\phi\left(\mathrm{x}_{\mathrm{k}}+\mathrm{x}_{\mathrm{k}+1}, \mathrm{u}_{\mathrm{k}}\right)$

where $\mathrm{x}_{\mathrm{k}-1}, \mathrm{x}_{\mathrm{k}}, \mathrm{x}_{\mathrm{k}+1}$ - states in the intervals $\mathrm{k}-1, \mathrm{k}$ and $\mathrm{k}+1$, respectively, $\mathrm{u}_{\mathrm{k}}$ - input in time interval $\mathrm{k}$ of the duration $\Delta \mathrm{t}$ and $\mathrm{x}_{-1}$ is the state at an appropriate time in the past. Further $\mathrm{x}_{0}$ is the initial state at a standardized 
time. Sustainability is defined in the period of time defined by the index-set of time intervals $k \in K=\{0,1,2, \ldots$, $\mathrm{k}+1\}$

The transformation of the state $x_{k-1}+x_{k}$ to the state $x_{k+1}$ under the influence of the input $u_{k}$ is defined by the mapping $\mathrm{f}$. Output function is defined by the mapping $\phi$. State is represented by the point in the state space and development is represented by the sequence of states at different instants, also called state trajectory.

Sustainable development cannot be the extension of the existing state. A salient feature of sustainability is the preservation of values of some state variables. The basic question is determining which state variables are to be sustained, and which are to be changed. The state variables that are sustained are referred as essential variables and their values will satisfy very strong constraints. From the system theory point of view, sustainable development will be realized if the essential state variables remain in the defined domain or point in state space during the whole time period $\mathrm{K} \Delta \mathrm{t}$. Essential variables $\mathrm{x}_{-1}, \mathrm{x}_{0}, \mathrm{x}_{1}, \mathrm{x}_{2}, \ldots \mathrm{x}_{\mathrm{e}}$ are elements of the set $\mathrm{X}_{\mathrm{E}} \subseteq \mathrm{X}$ where $\mathrm{X}$ is the set of all states.

The values of some of these variables, such as the consumption of some nonrenewable resources, some measures of pollution etc. have to be lower than certain determined limits. These constraints define one feasible region to which the state has to belong at any moment of the process. It means that trajectory in the state space, representing sustainable development, has to be located in the feasible region of the state space. It is pointed out, in 'A Report of the Club of Rome', published under the title: The Limits to Growth [9], that the restriction of the economic growth is the essential condition for achieving sustainable development. Figure 1 [9] presents the changes of a selection of state variables in the period between 1900 and 2100 (food per capita, resources consumption, pollution) and inputs (industrial output per capita, population). It is evident that during the whole period, state remains in one point of the state space. The achievement of this sustainable development is possible [9] by the application of the following measures: resources recycling, minimizing wastage, minimizing pollution, maximizing usefulness, achieving parity between birth rate and death rate, equalizing capital investment in industry to capital depreciation. The application of the state space concept is especially useful in cases when some regions in the state space have to be escaped. They are primarily the regions where values of the state variables representing the consumption of nonrenewable resources are above the predefined limits, or the regions where the values representing the pollution level are greater than the capacity of environment to absorb waste materials.

Figure1: Model of sustainable development (Source[9] ) Sustainable development also needs to meet the requirement of respecting the principle of intergeneration solidarity. This demand represents the necessity to enable the same or better life conditions for future generations and can be described by introduction of some function $g$ with the property:

$\mathrm{g}\left(\mathrm{x}_{\mathrm{k}}\right)>\mathrm{g}\left(\mathrm{x}_{\mathrm{k}-1}\right), \mathrm{k} \in \mathrm{K}$.

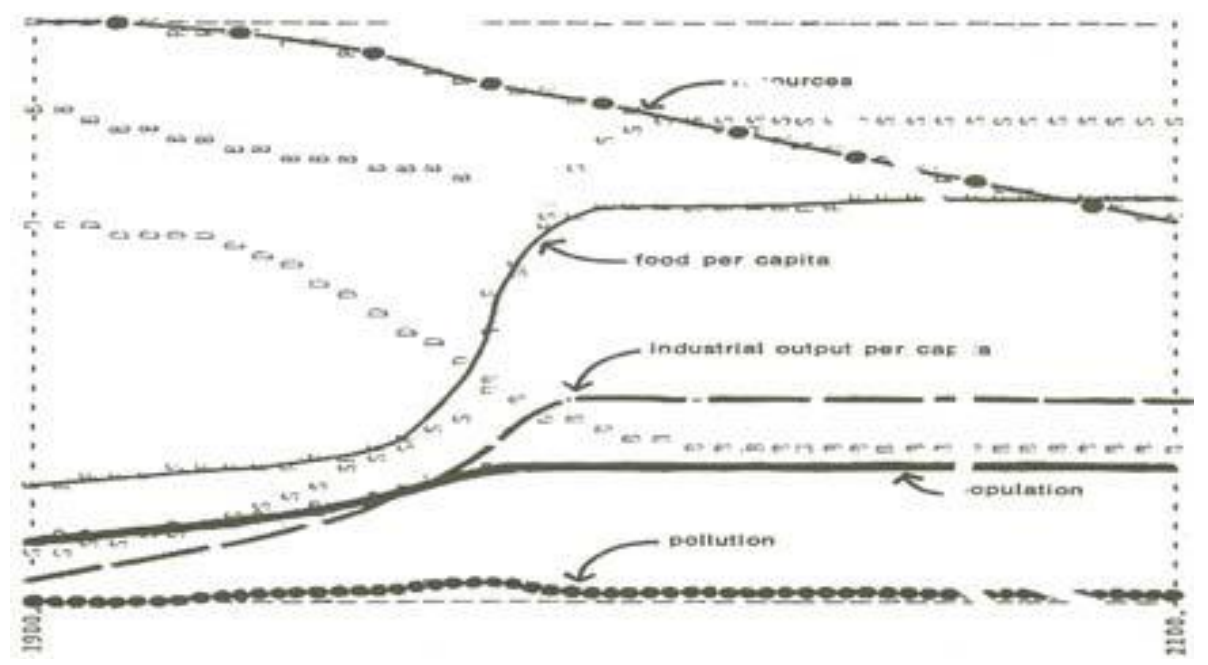

Figure1: Model of sustainable development (Source[9] )

Similar functions to $g$ were presented in the literature. Function of the system output can be influenced by a strong subjective component. Some output variables are very often, also the state variables. It could be capital stock expressed in monetary values and can also include ecological and social elements. In the Report of the Club of Rome, the function representing quality of life increases when industrial output and food per capita increase and pollution decreases. This expression (3) can also be used for a formal definition of sustainable development [5,13]. 


\section{Optimality And Sustainability Criteria}

The optimality criterion is among the fundamental concepts in not only operations research, but in a variety of other science disciplines such as system theory and systems management, mathematical optimization theory and mathematical programming, etc. It is generally said that an optimality criterion interprets a value system in each actual problem considered. In some cases, the task of selecting the optimality criterion is trivial.

However, in other cases the selection of the optimality criterion turns out to be a complex research problem itself. In a formal sense, an optimality criterion is a function or a functional in various forms and the central task of optimization is to determine the extreme value (or values) of the optimization function or the optimization functional.There are various models to solve such problems. These models are probabilistic or deterministic and the OR literature abounds in methods for determining the extremum or extrema, or at least, the values close to optimality criterion extremum/extrema. The first decades of OR development are characterized by insisting, in both theory and practice, on the existence of a single optimality criterion. It is regarded that even when several optimality criteria appear to exist, they have to be synthesized to a single criterion function (functional). This results not so much from believing that it is possible to interpret a value system in terms of a single performance measure, but rather from the need to avoid methodological difficulties faced when treating a problem with more than one optimality criterion. The development of OR has made it possible to overcome formal mathematical difficulties, and multicriteria optimization theories have undergone a very intensive development. Great progress has been recorded in the interpretation of value systems in planning and management tasks. A recent idea is that, apart from interpreting a value system in terms of several optimality criteria, it is of utmost importance to 'cover' all important aspects of the system environment managed by optimality criteria. This has given rise to a suggestion that optimality criteria be threefold in nature: sociological, economic and ecological. This is illustrated by the three well-known circles that form 7 subsets by intersecting. criterion.

One circle symbolizes sociological criteria, the second an economic and the third an ecological

Figure 2 shows four intersections. The intersection of all three circles is a subset symbolizing the field - Sustainability - $[2,1]$

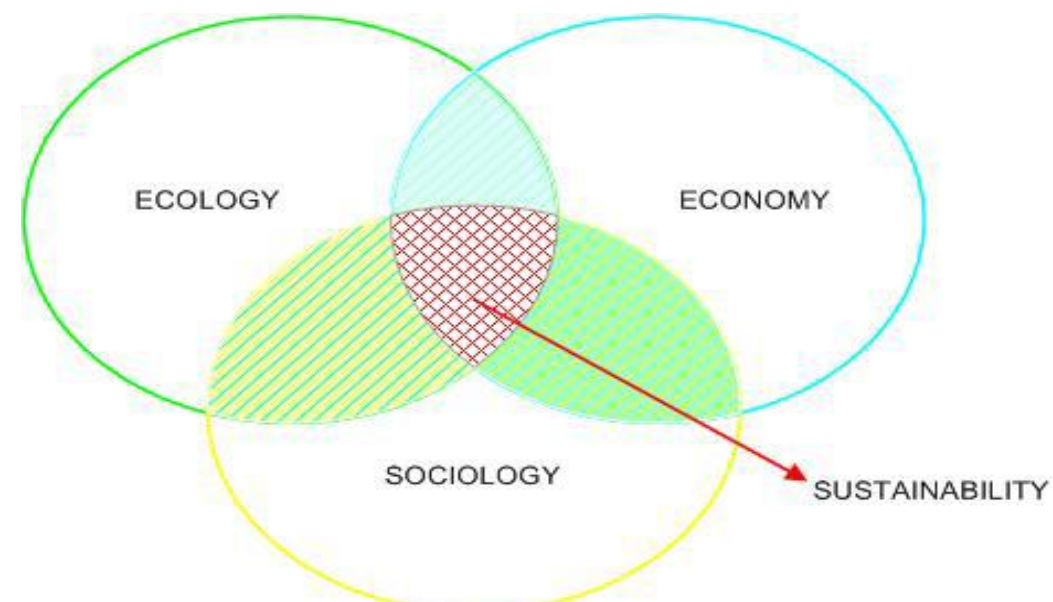

Figure 2 Threefold Nature of Optimality Criteria

The intersections of each of the two circles symbolize the following fields:

- Viability, economic and ecological criteria - $[10,6]$

- Equitability, sociological and economic criteria - $[1,4]$

- Bearability, sociological and ecological criteria - $[3,12]$

Sustainability criteria are defined on an abstract level as the mapping of input, control (or management action) and output on the vector space with real numbers as vector components.

$$
\mathrm{I} \times \mathrm{U} \times \mathrm{Y} \times \rightarrow \mathrm{V}(\mathrm{R})
$$

The mapping in (4) is not necessarily in analytical form. In solving problems in practice, very often there is a tendency to describe sustainability criteria in some appropriate analytical forms. Two analytical forms are in frequent use.

The first form is time discrete expressions where the sustainable criteria functions are generally the vector functions of all discrete time state variables and all discrete time control variables,

$F_{c}=F_{c}\left(x_{-1}, x_{0}, x_{1}, x_{2}, \ldots \ldots, x_{k}, u_{1}, \ldots \ldots, u_{k}\right), c=0,1, \ldots ., C$ 
Where $\mathrm{x}_{-1}$ is the state at an appropriate time in the past, $\mathrm{x}_{0}$ is initial state of the system, $\mathrm{k}$ denotes discrete time interval and $\mathrm{C}$ is the number of criteria in the vector sustainability function.

The second very common form of the sustainable criterion is vector functional as,

$\mathrm{F}_{\mathrm{c}}=\phi_{\mathrm{c}}\left[\mathrm{y}\left(\mathrm{t}_{\mathrm{f}}\right)\right]+\int_{t 0}^{t f} \mathrm{f}_{0}(\mathrm{u}, \mathrm{y}) \mathrm{dt}, \mathrm{c}=0,1, \ldots \ldots, \mathrm{C}$

where $t_{f}$ is the final time and $\mathrm{C}$ is the number of associated functionals.

Since its inception and wide acceptability over a period of five-decades, OR has now occupied the centre stage in solving the problems related to sustainability. As an example how OR has converged to the field referred to as Sustainability today. Firstly, we shall consider a conventional OR task economic allocation of electric energy production to thermal generation units in an electric power system. During the fifties and sixties of the previous century, energy production distribution to thermal generator units was treated as a strictly economic task with only one optimization criterion - energy production costs. Hundreds of papers addressing this issue, from purely theoretical to very practical ones, were published. Very diverse problem statements were treated - daily, weekly and annual dispatching, dynamic and non-dynamic versions, deterministic and stochastic variants, but all of them had only one optimization criterion - production cost or expected production cost which was to be minimized.

During the eighties and nineties, operations researchers started paying attention to the ecological aspects of these problems as well. $\mathrm{CO} 2$ and $\mathrm{NH} 3$ emissions of powdered matter increase in the temperature of generator cooling water fed to river flows began to figure as optimization criteria. Production allocation tasks became complex multicriteria optimization problems. The sociological component was added to energy production allocation problems in the first decade of this century. A performance measure involving some social aspects became one of the candidates for optimization criteria. This is how a classical OR task has transformed into a multicriteria optimization problem, the solution to which may be referred to as sustainable management, because it takes into account the economic, ecological and sociological performance measures and objectives[14].

From the OR perspective, sustainability means multicriteriality in both conceptional and methodological sense. Numerous multicriteria optimization methods are available for selecting sustainable strategies/management. As is well known, one of the key problems in multicriteria optimization is the issue of determining the relative importance of single optimization criteria. It is natural to approach this issue in a hierarchical way: first to determine the relative importance of criteria groups (sociological, economic, and ecological) and in the following steps, the relative importance of each criterion within each group. The known Analytical Hierarchy Process (AHP) could be a guide through this procedure.

We wish to underline a fact well known in OR - individual (expert) subjectivity in determining the relative importance of criteria is unavoidable. This is why we have to be careful in interpreting the results we obtain - sustainable strategies/management which inherently contains subjectivity.

\section{Conclusion}

The fundamental concepts and methods developed and adopted in the theory of the systems control and operations research area, are quite suitable from application point of view to the important problems of sustainability and leads to sustainable strategies. Use of the state space concept provides the exact statement of the sustainability and sustainable development problems. Many vital aspects of sustainability can be accurately treated with the use of OR and state space concepts. To begin with, it is quite simple to use state space concept, to locate and define feasible regions in which the data pertaining the pollution level are greater than environmental capacity to absorb waste materials. It is particularly useful in the cases when some regions in the state space need to be avoided. Further it is established that the concepts of viability, equitability and bear ability are closely related to the optimization criteria in OR.

A large number of system analysis and management methods developed in OR over the past few decades are well suited for use in the problems of determining sustainable strategies/management. We mention four groups of such methods that have a key role in the selection of sustainable strategies/management: (1) multicriteria analysis and multicriteria optimization methods, (2) forecasting methods, (3) simulation methods (4) non-conventional treatment of uncertainty. We will go one step further and claim that a real, optimal sustainable strategy/management cannot be determined without appropriate application of the stated OR methods. 


\section{References}

[1] Adams, W.M., "The future of sustainability, rethinking environment and development in the twenty first century", Report IUCN, 2006

[2] Allen, W., "Learning for sustainability", Sustainable Development, 2007.

[3] Donald Brown, 'The role of economics in sustainabledevelopment and environmental protection', in Sustainable Development: Science, Ethics and Public Policy, edited by John Lemons and Donald Brown, Kluwer Academic Publishers, Dordrecht, 1995, pp. $52-63$

[4] ESCAP. 1994. UN Economic and Social Commission for Asia and the Pacific Committee on Environment and Sustainable Development. Note by the Secretariat. E/ESCAP/ESD (2)/4.

[5] Galloppin, G., "A systems approach to sustainability and sustainable development”, UN Publication, Santiago, Chile, 2003.

[6] Hanley, N., Shorgen, J., and White. B., Environmental Economics in Theory and Practice,Palgrave, London, 2007.

[7] Harris, J.,'Basic principles of sustainable development”, Tufts University, Medford MA,USA, 2000.

[8] Munasinghe, M. (1993) Environmental Economics and Sustainable Development, World Bank Environment Paper Number 3, The World Bank, Washington, D.C.

[9] D. Meadows, D. Medows, J. Randers, and W. Berens III, The Limits to Growth, Universe Books, New York, 1972.

[10] Pearce, D., "An intellectual history of environmental economics", Annual Review of Energy and Environment, 27 (2002) 57-81.

[11] Sharon Beder, The Nature of Sustainable Development, 2nd ed., Scribe, Newham, 1996, ch. 9.

[12] Larry Lohmann, 'Dismal green science', Ecologist, vol. 21, no. 5, Sept./Oct. 1991, p. 194.

[13] Rajesh Dangwal, Arvind kumar\& Vivek Naithani, Optimization of air pollutant causing agents using Goal Programming Techniques, Journal of Mountain Res. vol-6 pp. 129-133.

[14] Manfred Schidlowski, Human activities and environmental stress some essential revisited, Terra Nova, 3,472- 476(1991) 